\title{
Canine Uterine Leiomyoma with Epithelial Tissue Foci, Adenomyosis, and Cystic Endometrial Hyperplasia
}

\author{
George S. Karagiannis, Mihalis Pelekanis, Panayiotis Loukopoulos, \\ Haris N. Ververidis, and Eleni Kaldrymidou \\ School of Veterinary Medicine, Aristotle University of Thessalonki, Aristotle University of Thessalonki, 54124 Thessaloniki, Greece \\ Correspondence should be addressed to George S. Karagiannis, gkaragiannis@mtsinai.on.ca
}

Received 9 May 2011; Accepted 31 May 2011

Academic Editors: C. Hyun and J. Orós

Copyright ( $) 2011$ George S. Karagiannis et al. This is an open access article distributed under the Creative Commons Attribution License, which permits unrestricted use, distribution, and reproduction in any medium, provided the original work is properly cited.

\begin{abstract}
An 11-year-old Labrador Retriever bitch with a history of intermittent, sanguineous vaginal discharge of a six-month duration was presented. During exploratory laparotomy, two well-delineated, intramural masses were identified bilaterally in the uterine horns. Histopathologic examination of the mass on the left horn showed that it was a typical leiomyoma. However, the second mass appeared with an unusual coexistence of histological lesions, involving epithelial tissue foci, mild focal adenomyosis, and cystic endometrial hyperplasia. Interestingly, such combination was never encountered before in dogs. Although uterine leiomyoma is quite usual in the reproductive system of female dogs, this case resembled relevant cases of human uterine adenomyomas in morphology, and thus it was offered a similar tentative diagnosis.
\end{abstract}

\section{Background}

The uterine glands occasionally proliferate and penetrate the myometrium, resulting in a condition known as adenomyosis; in the dog and the cat, adenomyosis is rare and is usually found as an incidental lesion accompanying pathological changes of the uterus, including endometritis, pyometra, or endometrial cystic hyperplasia [1]. However, neoplastic lesions of the uterus accompanied by adenomyosis have not been reported before in the dog. Here, a very rare clinical case of a female dog with two uterine leiomyomas, one of which contained foci of epithelial cells, and at the same time, accompanied by adenomyosis and cystic endometrial hyperplasia, is presented.

\section{Case Description}

An 11-year-old Labrador Retriever bitch weighing $25.3 \mathrm{~kg}$ was presented to a veterinary clinic in Limassol, Cyprus with a history of intermittent, sanguineous vaginal discharge of a six-month duration that was not associated with urination or pain. According to the owner, the bitch was nulliparous, never bred or steroid hormone treated, and had displayed signs of oestrus two months before admission. At clinical examination the dog was alert, and deep abdominal palpation revealed the presence of several small masses in the midcaudal abdomen. Vulvar and vaginal examination showed no other significant findings except for a small quantity of sanguineous fluid. Haematological, biochemical, and urinalysis findings were within normal limits. Radiographic examination of the thorax showed no significant findings apart from the presence of mild lung calcinosis that could be attributed to the dog's old age. Radiographic examination of the abdomen showed a mild enlargement of the uterus (Figure 1(a)). Therefore, a tentative diagnosis of pyometra was offered and exploratory laparotomy was performed.

During exploratory laparotomy, two well-delineated, intramural masses were identified bilaterally in the uterine horns and ovariohysterectomy was performed. On gross examination (Figure 1(b)), both masses were oval, firm, with smooth surface, and their margins were penetrated by many superficial veins. The mass on the left horn had a diameter of $3 \mathrm{~cm}$ while the other on the right horn $5 \mathrm{~cm}$. The ovaries had cystic appearance due to many thin walled 


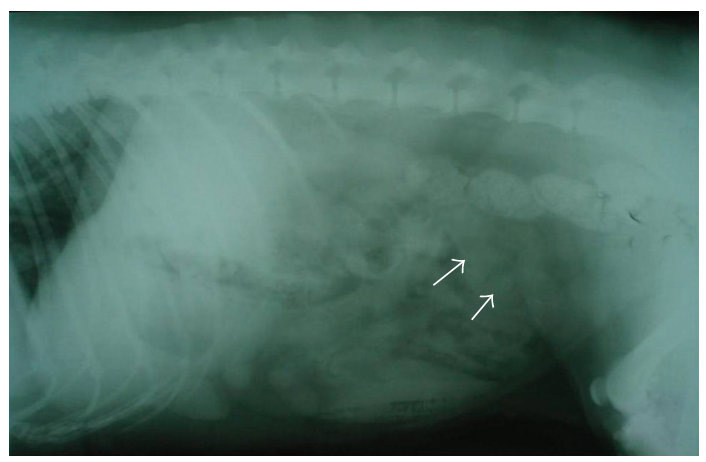

(a)

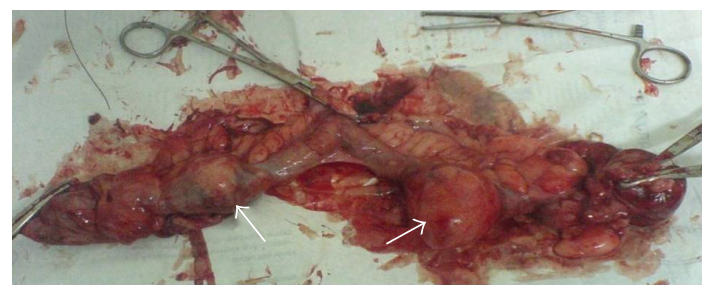

(b)

FIgURE 1: (a) Lateral abdominal radiograph of the bitch showing evidence of mild segmental enlargement of the uterus (arrows). (b) The excised uterus with distinct masses (arrows) in both horns.

ovarian cysts of 1-14 $\mathrm{mm}$ diameter with either reddish or translucent fluid along with a total of seven projecting regressing corpora lutea of $3.5 \mathrm{~mm}$ diameter. Portions of the uterine masses were fixed in $10 \%$ neutral formalin, processed routinely, embedded in paraffin, and $5 \mu \mathrm{m}$-thick sections were stained with haematoxylin and eosin. The bitch recovered uneventfully and remains clinically healthy at present, 12 months after the initial presentation.

Histopathologic examination of the mass on the left horn showed that it was a leiomyoma. The tumour cell population was composed of mildly pleomorphic muscle cells arranged in interlacing bundles and was well vascularised, although a small necrotic area was noted. Examination of the mass on the right horn revealed a mixed tumour with both mesenchymal and epithelial elements, the former being the dominant component. The tumour was overall well demarcated. The mesenchymal component was mainly composed of welldifferentiated smooth muscle cells arranged in streams or interlacing bundles (Figure 2(a)). The neoplastic cells were moderately pleomorphic and had spindle or oval, often large, vesicular nuclei; few mitoses were observed. Several epithelial foci were also observed within the mesenchymal component of the tumour, forming roundish nests of varying size (Figure 2(b)). These foci contained epithelial cells the morphology of which was reminiscent of glandular steroid hormone-synthesising cells, especially those of corpus luteum, possibly granulosa lutein cells and theca lutein cells, or those of the adrenal cortex, possibly zona fasciculata cells (Figure 2(c)). An area of necrotic or degenerating tissue was detected in the center of the biggest epithelial focus (Figure 2(b)). In the endometrium adjacent to this lesion, variably sized endometrial glands were observed extending between the muscle bundles of the myometrium to a moderate degree (Figure 2(d)). The endometrium was hyperplastic; some endometrial glands were distended to a variable degree and were cystic, containing noninflammatory material or blood (Figure 2(d)). No bacterial growth was observed. A diagnosis of a leiomyoma containing epithelial tissue foci and being adjacent to mild focal adenomyosis and mild cystic endometrial hyperplasia was offered.

\section{Discussion}

Leiomyomas, accounting for $85-90 \%$ of all canine uterine tumours, are the most common tumours of the tubular genitalia in the dog and are usually multiple and, in some unknown manner, endocrine dependent. They are frequently associated with ovarian follicular cysts or oestrogen-secreting tumours and are often also associated with endometrial hyperplasia, mammary hyperplasia, and mammary neoplasia [1]. They consist of neoplastic cells of smooth muscle differentiation accompanied by varying quantities of connective tissue and lack a glandular component [2, 3]. In the case presented here, one of the uterine leiomyomas presented was associated with endometrial cystic hyperplasia and adenomyosis, a combination of lesions that has never been reported before in the literature. Cystic endometrial hyperplasia is the most common among the cystic lesions of the canine uterus and is most frequently associated with pyometra [4]. On the other, hand canine uterine adenomyosis is occasionally reported in the literature; StöcklinGautschi et al. [5] reported two cases of focal adenomyosis in two bitches that both gave rise to clinical signs; Tamada et al. [6] reported a dog with adenomyosis with severe inflammation of the uterine cervix; a case of endometrial polypoid adenomyomatosis, an entity that is very close to but distinct from adenomyosis, has been described in a bitch with ovarian granulosa cell tumour and pyometra [7]. Apart from dogs, uterine adenomyosis has also been encountered in the cat and cow $[8,9]$. However, adenomyosis was not associated with a uterine neoplasm, as in our case, in any of the above mentioned reports.

Adenomyosis can be experimentally induced in certain strains of laboratory mice; the incidence can be markedly enhanced by systemic exposure to various hormonal agents, including prolactin, progesterone, synthetic progestins, pituitary isografts, and certain oestrogenic agents, as well as tamoxifen and toremifene [10-13]. Therefore, it seems that hormonal disturbances play a crucial role in the development of uterine adenomyosis. In the cases of canine uterine adenomyosis and adenomyomatosis presented by Tamada et al. [6] and Zanghì et al. [7], respectively, as well as in the case presented here, such endocrine disturbances seem to be present. Endocrine-related cancers, as in the case of the ovarian granulosa cell tumour presented by Zanghì et al. [7], can be a common cause of hormonal dysregulation. In our case, accordingly, the presence of cystic endometrial hyperplasia as well as the evidence of nonendometrial epithelial tissue within the leiomyoma may indicate endocrinedysregulation, a possible mechanism that could partially 


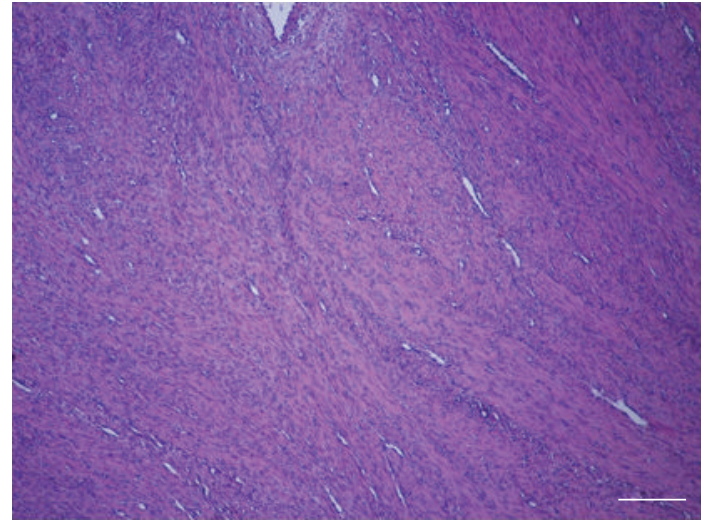

(a)

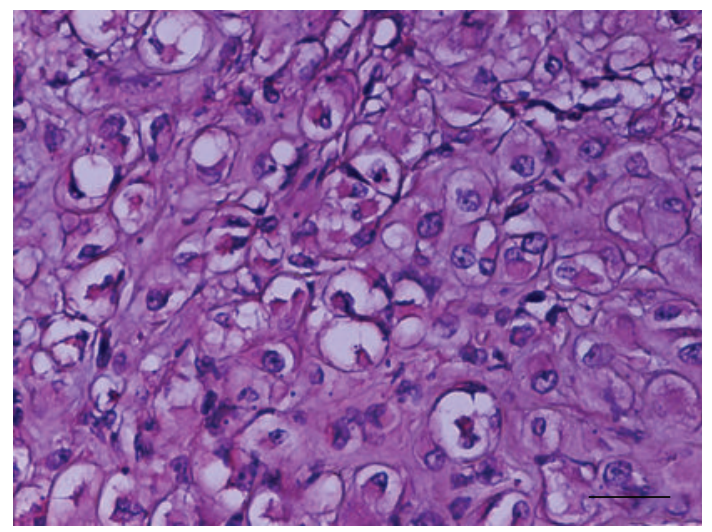

(c)

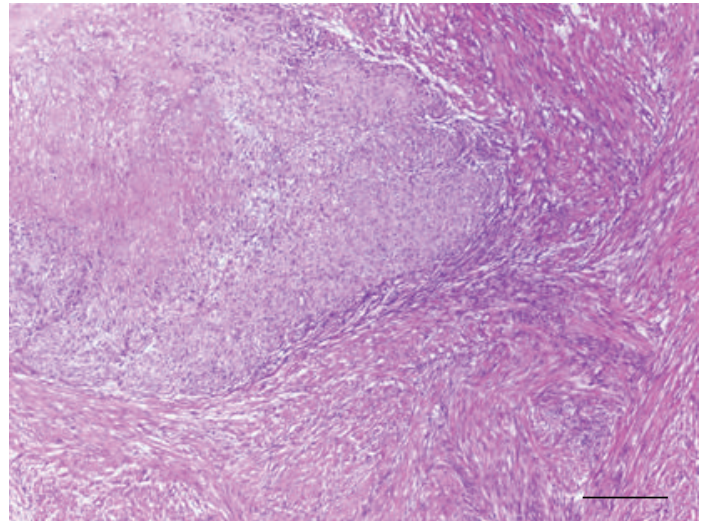

(b)

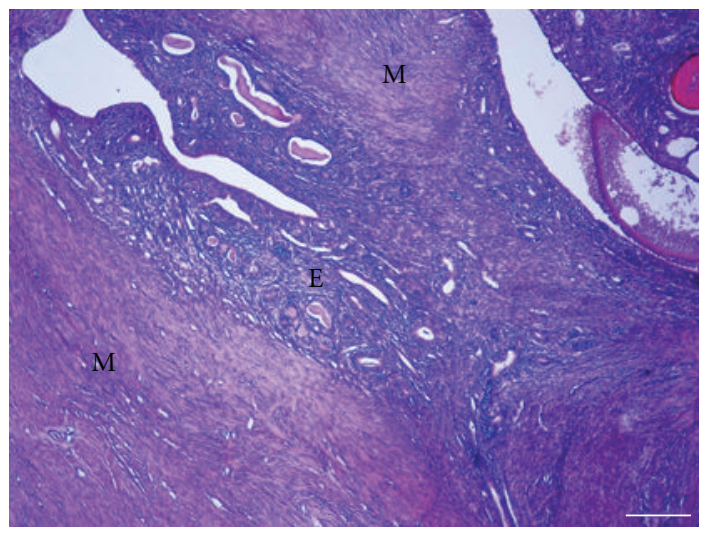

(d)

Figure 2: Histological presentation of the lesions described. Leiomyoma (a, b, c) containing epithelial tissue (b, c). (a) The mesenchymal component of the tumour was composed of well-differentiated smooth muscle cells arranged in streams or interlacing bundles. H\&E, bar $=200 \mu \mathrm{m}$. b and c Epithelial foci. (b) H\&E, bar $=1000 \mu \mathrm{m}$. (c) H\&E, bar $=62.5 \mu \mathrm{m}$. (d) Mild adenomyosis and mild cystic endometrial hyperplasia. Hyperplastic endometrial glands $(\mathrm{E})$, some cystic, extending between the muscle bundles of the myometrium $(\mathrm{M})$. $\mathrm{H} \& \mathrm{E}, \mathrm{bar}=$ $200 \mu \mathrm{m}$.

explain the development of adenomyosis. However, the cases presented by Stöcklin-Gautschi et al. [5] did not appear to have hormonal dysfunction, because the areas of the uterus without adenomyosis were histologically normal. The latter report renders the knowledge on the pathogenesis of uterine adenomyosis less concrete and therefore the aetiology of this clinicopathological entity remains to be elucidated.

Leiomyomas are neoplasms of mesenchymal origin and thus they lack a glandular component [2]. In this case, the presence of nonendometrial epithelial foci within the leiomyoma is indeed controversial. Their morphology resembled that of luteal or adrenocortical tissue. The presence of luteal tissue could be hypothesised to be more likely if the leiomyoma on the right horn had engulfed part of the proximal ovary; however, that mass was positioned at a considerable distance (at least $6 \mathrm{~cm}$ ) from the respective ovary (Figure 1(b)). Also, ectopic ovarian-luteal tissue seems unlikely in the absence of microscopic evidence of any other ovarian tissue concurrently present with these epithelial foci. Another valid assumption may be that the foci are of ectopic or accessory cortical adrenal tissue (cortical adrenal rests) surrounded by the leiomyoma. According to reports in [14], these are adrenal cortex fragments that are separated from the mesodermal ridge during embryogenesis and form inactive-unless-stimulated nests at sites such as the retroperitoneum, the broad ligament, the ovaries and the inguinal region. Ectopic adrenal tissue, although common in human pediatric records, is seldom reported in domestic animals, including the dog [15]. In any case, the neoplasm gave the impression of a Mullerian mixed tumour consisting of both mesenchymal and epithelial elements [16] and more specifically it could be claimed that it shared many common features with neoplasms known as adenomyomas, as described in the human literature [17]. To the authors' knowledge, such case of a uterine leiomyoma containing nonendometrial epithelial foci, associated with adenomyosis and/or cystic endometrial hyperplasia has never been described before.

\section{Acknowledgment}

The authors wish to gratefully acknowledge Dr. Polys Cr. Pittas and Dr. Sotiris Christophi for allowing them to handle and present this case. 


\section{References}

[1] M. K. Klein, "Tumors of the female reproductive system," in Small Animal Clinical Oncology, S. J. Withrow and E. G. MacEwen, Eds., pp. 445-454, Saunders, Philadelphia, Pa, USA, 3rd edition, 2001.

[2] R. S. Brodey and J. F. Roszel, "Neoplasms of the canine uterus, vagina, and vulva: a clinicopathologic survey of 90 cases," Journal of the American Veterinary Medical Association, vol. 151, no. 10, pp. 1294-1307, 1967.

[3] N. J. MacLachlan and P. C. Kennedy, "Tumors of the genital systems," in Tumors in Domestic Animals, D. J. Meuten, Ed., pp. 547-573, Iowa State Press, Ames, Iowa, USA, 4th edition, 2002.

[4] D. H. Schlafer and A. T. Gifford, "Cystic endometrial hyperplasia, pseudo-placentational endometrial hyperplasia, and other cystic conditions of the canine and feline uterus," Theriogenology, vol. 70, no. 3, pp. 349-358, 2008.

[5] N. M. Stöcklin-Gautschi, F. Guscetti, I. M. Reichler, U. Geissbühler, S. A. Braun, and S. Arnold, "Identification of focal adenomyosis as a uterine lesion in two dogs," Journal of Small Animal Practice, vol. 42, no. 8, pp. 413-416, 2001.

[6] H. Tamada, N. Kawate, T. Inaba et al., "Adenomyosis with severe inflammation in the uterine cervix in a dog," Canadian Veterinary Journal, vol. 46, no. 4, pp. 333-334, 2005.

[7] A. Zanghì, G. Catone, G. Marino, M. Quartuccio, and P. A. Nicòtina, "Endometrial polypoid adenomyomatosis in a bitch with ovarian granulosa cell tumour and pyometra," Journal of Comparative Pathology, vol. 136, no. 1, pp. 83-86, 2007.

[8] H. B. Gelberg and K. McEntee, "Pathology of the canine and feline uterine tube," Veterinary Pathology, vol. 23, no. 6, pp. 770-775, 1986.

[9] K. McEntee, "The uterus: atrophic, metaplastic and proliferative lesions," in Reproductive Pathology of Domestic Animals, K. MacEntee, Ed., pp. 167-190, Academic Press, San Diego, Calif, USA, 1990.

[10] P. Greaves and I. N. H. White, "Experimental adenomyosis," Best Practice and Research: Clinical Obstetrics and Gynaecology, vol. 20, no. 4, pp. 503-510, 2006.

[11] T. Mori, H. Nagasawa, and S. Takahashi, "The induction of adenomyosis in mice by intrauterine pituitary isografts," Life Sciences, vol. 29, no. 12, pp. 1277-1282, 1981.

[12] H. Nagasawa, M. Ishida, and T. Mori, "Effects of treatment with prolactin or progesterone on the coincidence of mammary tumors and uterine adenomyosis in young SHN mice," Laboratory Animal Science Chicago, vol. 37, no. 2, pp. 200-202, 1987.

[13] P. L. Ostrander, K. T. Mills, and H. A. Bern, "Long-term responses of the mouse uterus to neonatal diethylstilbestrol treatment and to later sex hormone exposure," Journal of the National Cancer Institute, vol. 74, no. 1, pp. 121-135, 1985.

[14] T. D. Barwick, A. Malhotra, J. A. W. Webb, M. O. Savage, and R. H. Reznek, "Embryology of the adrenal glands and its relevance to diagnostic imaging," Clinical Radiology, vol. 60, no. 9, pp. 953-959, 2005.

[15] G. Prasad and R. D. Sinha, "Occurrence of accessory adrenal cortical nodule in the domestic animals," Indian Journal of Animal Sciences, vol. 50, pp. 1060-1063, 1980.

[16] Y. Ohta, T. Suzuki, A. Shiokawa, and H. Ota, "A case of uterine adenomyoma with bizarre smooth muscle cells mimicking leiomyosarcoma," Diagnostic Cytopathology, vol. 32, no. 5, pp. 288-291, 2005.

[17] C. J. R. Stewart, Y. C. Leung, R. Mathew, and A. L. McCartney, "Extrauterine adenomyoma with atypical (symplastic) smooth muscle cells: a report of 2 cases," International Journal of Gynecological Pathology, vol. 28, no. 1, pp. 23-28, 2009. 

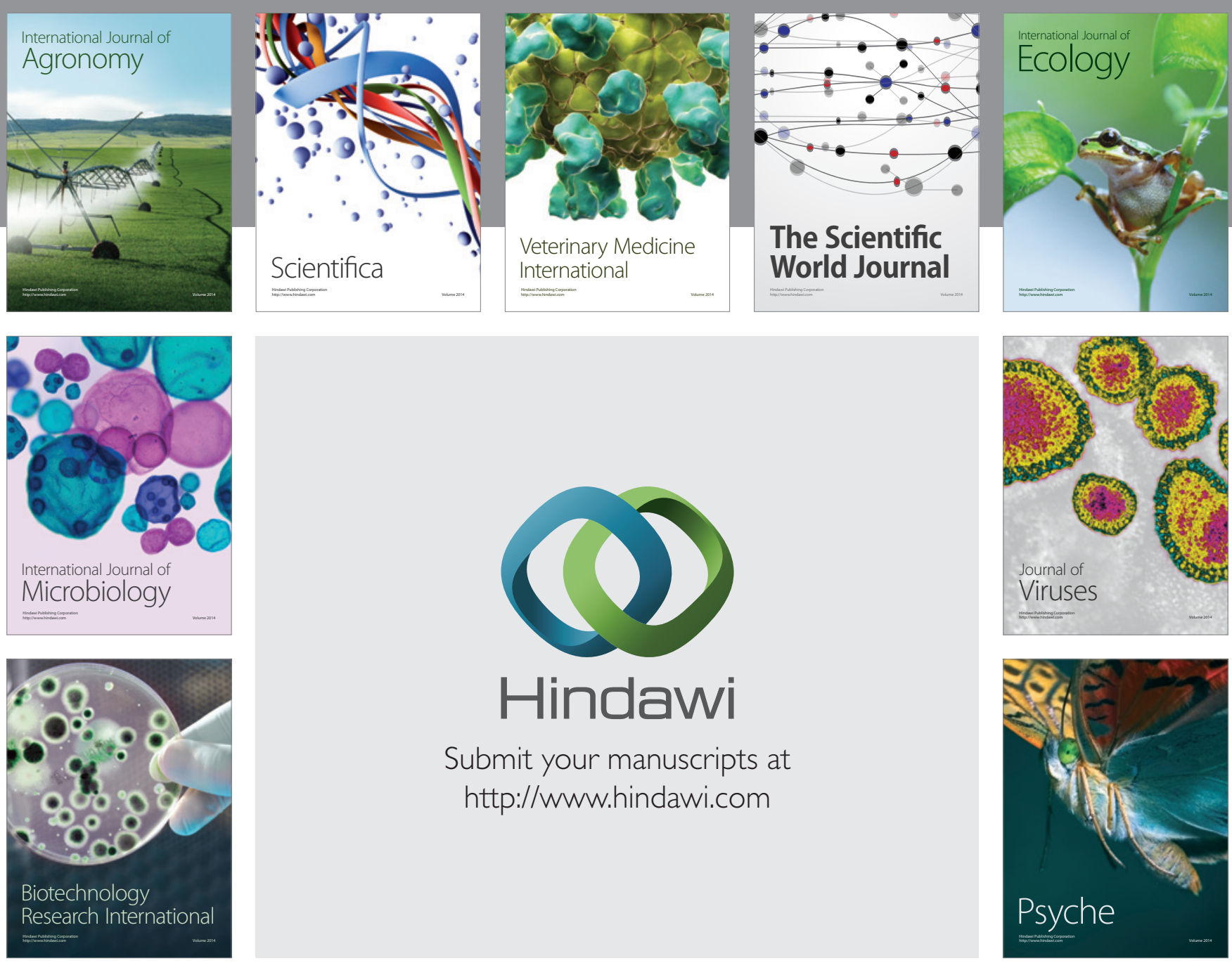

Submit your manuscripts at

http://www.hindawi.com
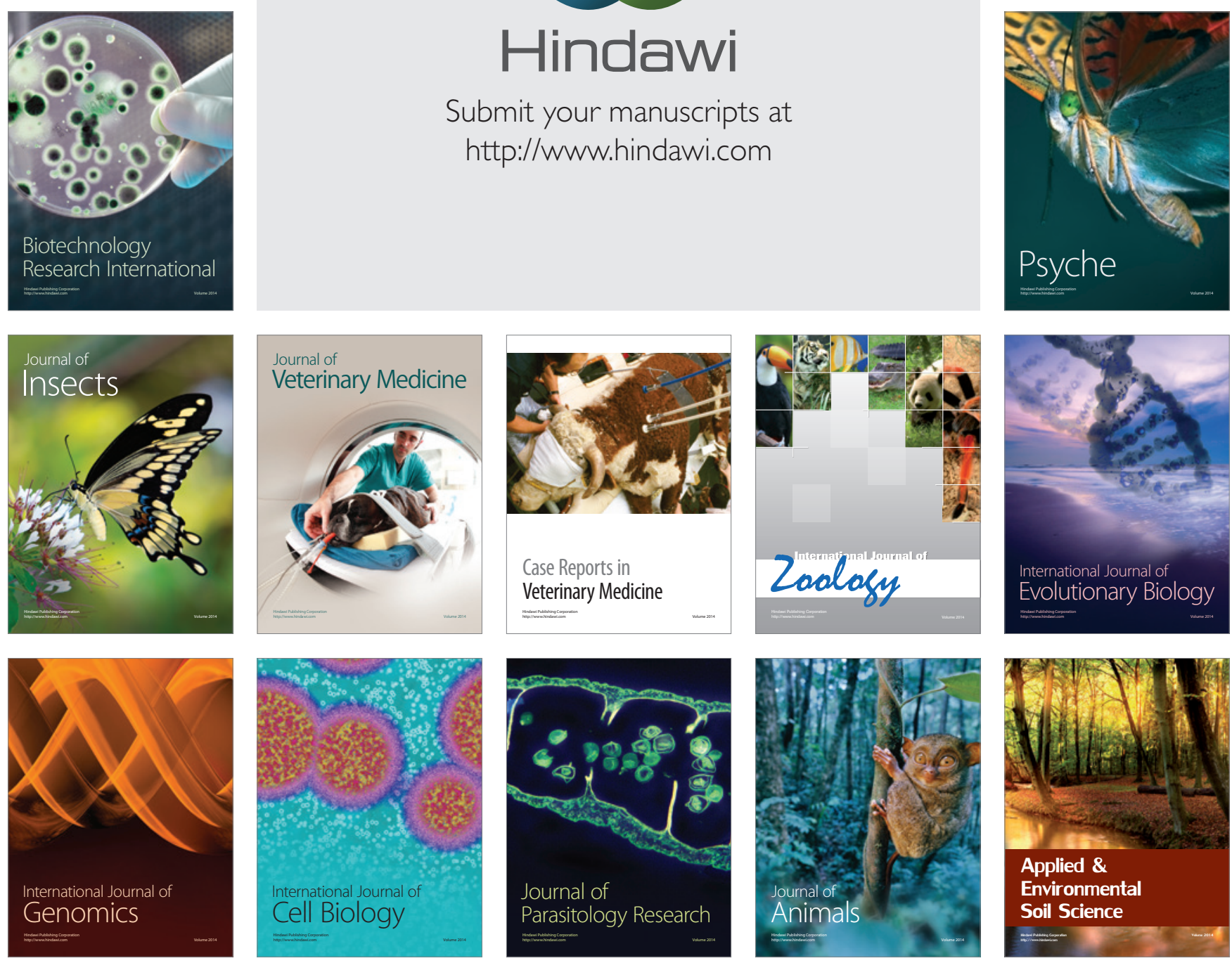